\title{
Instability of development and fractal architecture in dryland plants as an index of grazing pressure
}

\author{
C. L. Alados*, J. M . Emlent, B. Wachockił \& D. C. Freeman§ \\ *Instituto Pirenaico de E cología, A vda. M ontanãna 177, A ptado. 202, \\ 50080 Zaragoza, Spain \\ †N orthwest B iological Science Center (NBS), 6505 NE $65^{\text {th }}$ Str., Seattle, \\ W A 98115, U.S.A. \\ ¥Center for Environmental Services, C ollege of Science, W eber State \\ U niversity, O gden, U tah 84408, U.S.A. \\ $\S D$ epartment of B iological Sciences, W ayne State U niversity, D etroit, M I \\ 48202, U.S.A.
}

(Received 13 M ay 1997, accepted 28 J uly 1997)

\begin{abstract}
D evelopmental instability has been used to monitor the well-being of natural populations exposed to physical, chemical and biological stressors. H ere, we use developmental instability to assess the impact of grazing on Chrysothamnus greenii and Seriphidium novum shrubs, and O ryzopsis hymenoides grass, common in the arid intermountain west of the U S.A. Statistical noise in allometric relations was used as an indicator of developmental instability arising from grazing-induced stress. U npalatable species that are not grazed (Chrysothamnus greenii) or species that are dormant during the winter-spring grazing period ( 0 ryzopsis hymenoides) show lower allometric variability under high grazing pressure. Palatable species (Seriphidium novum) exhibit high developmental instability under low and high grazing pressure. Grazing pressure imposed by presumably co-adapted wild herbivores enhances developmental stability in species habituated to moderate grazing, like O ryzopsis hymenoides, but stresses plants such as Chrysothamnus greenii that prefer disturbed environments. These grazing effects are probably due to the impact grazing has on competitive relationships and not to the direct action of the herbivore on the plants.
\end{abstract}

C1998 A cademic Press Limited

Keywords: developmental instability; fractal architecture; grazing; Chrysothamnus; Oryzopsis; Seriphidium

\section{Introduction}

D evelopmental stability, the ability of a genotype to consistently produce a given phenotype in a given environment, has been shown to decline as a result of genetic stresses such as inbreeding or hybridization between disparate taxa, and as a result of exposure to both physical and chemical stressors (see Markow (1994) for a review). 
Developmental instability is manifested as developmental error reflected in exaggerated intra-individual variation in repeated traits and patterns.

T raditionally, developmental instability has been measured by random deviations away from bilateral symmetry, fluctuating asymmetry (Eumner \& Huestis. 192.1: udwia. 1932; cited in Van Valen, 1962; see Palmer \& Strobeck, 1986; and Graham et al., 1993a), and increases under stress. For example, audiogenic stress increased left-right differences in rats (Siegel \& Smookler, 1973; : Siegel \& D oyle, 1975a). Temperature stress also caused increased fluctuating asymmetry in rats and mice (Beardmore, 1969; Siegel \& D oyle 1975b, c; Siegel et al. 1977) and in the salmon O ncorhynchus keta Walbaum (B eacham, 1990). Fluctuating asymmetry increased in grunion (L euresthes tenuis) exposed to DDT (Valentine \& Soulé, 1973). Similar results were observed by McKenzie \& Clarke (1988) in the blowfly, M usca vetustissima Walker, exposed to Avermectin. However, bilateral symmetry is only one of many measures of developmental instability. Other kinds of symmetry in development - radial symmetry, translational symmetry, and symmetry of spatial scale (Ereeman et al., 1993; Graham et al, 1993a; Alados et al., 1994, in press; Escós et al. 1995d. 1997) - have also proven useful in detecting and assessing the biological effects of stress.

Until recently most studies concerned animals with bilateral symmetry, though studies have now revealed that plants also are suitable subjects to detect developmental instability caused by environmental disturbance (Ereeman et al. 1993. 1995: Alados ef

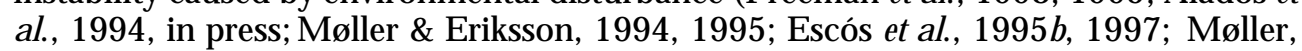
1995al; Uracy et al. 1995: Sherry \& L L ord. 1996).

The extent to which developmental instability reflects the ability of an organism to increase fitness will depend on the character analysed. T raits that directly and strongly affecting fitness and are under intense stabilizing selection may not be appropriate for developmental instability analysis (Soulé \& Cuzin-Roudy, 1982). On the other hand, high plastic characters may present high developmental instability even under good conditions. In consequence, in choosing measures of developmental instability it will be useful to consider alternate developmental instability measurements. Plants, because of their modular nature and taxon-specific consistent architecture, present repeated allometries (i.e. branch diameter, branch length, and dry weight; Kimura 1960, Ogawa \& K ira, 1977; Kohyama, 1987; Wiklas, 1992) that can be used to assess developmental instability. In allometric relations, variables are related by a power law. Power law scaling results from self-similarity, which means that each part of an object resembles the whole object. F or example, the branch system of a plant consists of selfsimilar branches. Self-similar structures can be analysed via their fractal dimension, which is a measure of how throughly they fill space, and thus how efficiently they interact with their environment; complex, space-filling structures are characterized by high fractal dimension (Zeide \& P feifer, 1997); Bassingthwaighte et al., 1994; Bunde \& Havlin, 1995). There are several types of fractal dimension, including capacity dimension, information dimension, correlation dimension, and the $L$ yapunov dimension, and there are several different algorithms to compute fractal dimension; but until methods of fractal analysis are standardized it will be difficult to compare fractal dimension values taken out of the context of a given study. In spite of this, application of fractal analyses to biology is rapidly increasing. H ere we not only use statistical noise in allometric relations, but also complexity of fractal structures as a way to detect disturbances in natural ecosystems.

Few studies have examined the influence of natural biotic stressors on developmental stability. Zakharov et al. (1991) have shown that in some populations of the common shrew, Sorex, developmental stability is lowest when the local population density is the highest. Several authors (Eolak. 1994; Escós et al. 1995a, b; M đoller 1995b; Alados et al. 1996. M ara \& F reeman, unpublished data) have shown that developmental stability declines as parasite loads or disease increases, provided that 
the parasitism occurs before the cessation of development. But in general, developmental stability has not been used to assess the impact of one species upon another. Y et, developmental stability has much to offer as a means of assessing the impact of interspecific interactions, and specifically to the understanding of grazing systems.

The 'beneficial' effects of grazing have been the subject of considerable debate (McN aughton, 1977, 1979, 1983, 1986; Belsky, 1986, 1987; Crawley, 1987, 1992). $\mathrm{G}$ razing has been shown to change plant community structure (Caraill \& /efferies. 1984: Ruess \& M cN auahton. 1987; llefferies. 1988; Brown \& Gange. 1989; Ruess et al., 1989; M clnnes et al., 1992); M ontalvo et al., 1993), and to affect life history feature of both grazed and non-grazed species. The effects of grazing depend upon the intensity and frequency of damage (Harper, 1977; [Crawley, 1983; M arquis. 1984] 1992, Doak, 1991; Edenims et al. 1993), the plant phenological stage at the time of herbivory (Maschinski \& Whitham, 1989; Marquis, 1992), which plant tissues are removed (Brown \& Gange. 1989; O Oesterheld, 1992), competition with non-grazed species (E owler \& Rausher. 1985; M aschinski \& Whitham. 1989), and the biological characteristics of the plant species in question (Brown \& Gange, 1989). The methodology traditionally used to detect grazing effects is thoroughly discussed by Belsky (1986, 1987), and Trlica \& Rittenhouse (1993); it is time-intensive. Developmental instability, on the other hand, is relatively inexpensive and quickly provides an assessment of stress.

$\mathrm{H}$ ere, we analyse the effects of plant competition in response to different herbivore pressure on developmental stability of one non-grazed shrub species (Chrysothamnus greenii A. G ray), a palatable shrub species (Seriphidium novum (N elson) W. H. W eber (syn. A rtemisia nova N elson)), and one grass species (O ryzopsis hymenoides (Roem. \& Schultes) Ricker) subjected to long-term grazing experiments. In addition, we propose several new measures of developmental stability.

\section{Methods}

Study areas and species

The D esert Experimental Range (DER) of the USD A F orest Service is located in the cold desert shrub-steppe of western U tah. It has been the subject of a continuous grazing experiment since its inception in 1933 (see Clary \& Holmgren (1982) for a description of the DER and long-term grazing experiment). Plants exposed to three levels of winter grazing by sheep (light, medium and heavy with 25, 35 and 42 sheep days ha ${ }^{-1}$, respectively) (Hutchings, 1966) and a control area that is naturally grazed by pronghorn, jackrabbits and cottontail rabbits (the most important herbivore species inhabiting the DER) were examined.

Populations of O ryzopsis hymenoides, a perennial winter dormant grass, and a preferred food species for domestic animals, and two shrubs Chrysothamnus greenii (a rabbit brush inhabiting disturbed habitats and not preferred by sheep) and Seriphidium novum (black sagebrush, a long-lived woody plant highly preferred by domestic animals and antelope) were examined.

$\mathrm{H}$ ealthy plants of similar size were chosen in order to reduce variability in the analysis. A randomized branch sampling was performed, where the crown was divided into strata of similar size based on relative height and orientation, and one well developed branch was randomly selected from the specific strata. Additionally, in order that the loss of material as a direct effect of grazing did not interfere with plant architecture, only undamaged stems were selected for the analyses. In consequence, the effect of grazing pressure was studied on the undamaged plant part. 


\section{D ata collection}

Individuals of $\mathrm{C}$. greenii and 0 . hymenoides were collected from the Desert Experimental Range during July 1992. Samples were collected from 89 C. greenii plants, 39 of them in areas heavily grazed by sheep, 12 in moderately grazed areas and 38 in the control area. T wo undamaged stems per plant were measured. A total of 160 individuals of 0 . hymenoides were collected, 40 from each of the four grazing treatment areas, in two separate replicates. Seriphidium novum was collected between the end of $M$ ay and the beginning of June 1993. Seventeen plants were collected from four small fenced grazing exclosures and 20 from the heavily grazed area outside the exclosures. To control for the effects of plant size and age, height, base perimeter, and two orthogonal crown diameters was measured for each pant.

\section{Data analysis}

Relationship between internode length and node order

The relation between internode length and node number from bottom to top fits a simple general equation with different species having different coefficients. Chrysothamnus greenii and $\mathrm{S}$. novum it the following expression:

$$
\mathrm{L}=\mathrm{kN} \mathrm{e}^{\mathrm{a}} \mathrm{bN}
$$

where $\mathrm{N}$ is node number, and $\mathrm{k}$, $\mathrm{a}$ and $\mathrm{b}$ are fitted constants unique to each plant. T aking natural logarithms of both sides of the equation:

$$
\ln (\mathrm{L})=\ln (\mathrm{k})+\mathrm{a} \ln (\mathrm{N})-\mathrm{bN}
$$

Stress is predicted to decrease the fit of these equations, so the standard error of the regression, $\mathrm{S}_{\mathrm{yx}}$, and the standard error of the parameter $\mathrm{a}, \mathrm{S}_{2}$, are good estimators of developmental instability (Ereeman et al., 1993; Graham et al. 1993a). L ow $R^{2}$ also indicates developmental instability. Regressions were performed separately for each plant and the resulting data were then analysed using mixed model analysis of variance, with herbivory treatments as a fixed effect factor and stem nested with treatments as a random effect factor, since two stems per individual plant were measured. In order to avoid side effects, all the plants were of similar size.

\section{Cumulative frequency exponent}

Chrysothamnus greenii has numerous leaves per stem, arranged at increasing distance from bottom to top. The increment of stem length $\left(\Delta \mathrm{L}_{(\mathrm{N})}\right)$ with increasing order from bottom to top fits to a hyperbolic function, where stem length $L$, with respect to node order $\mathrm{N}$, is given by:

$$
\Delta \mathrm{L}_{(\mathrm{N})}=\mathrm{kN}^{\mathrm{D}}
$$

This relation has the form of a cumulative frequency equation; using node order, $\mathrm{N}$, as a measure of scale, $D$ therefore fits the definition of a fractal dimension (Hasting $\&$ Sugihara 1993). This equation is similar to the mass-radius relation in lattice models (Avnir. 1990). D can be fitted with a regression analysis of the log transformed data. The error in the curve fitting is also a measure of developmental instability. Consequently, we used the standard error of the regression, $\mathrm{S}_{\mathrm{yx}}$, standard error of the slope $D, S_{D}$, and one minus the coefficient of determination $R^{2}$, as estimators of developmental instability. To test differences among treatments a mixed model analyses of variance was performed for the scaling parameter $D$ and curve fitting indexes, $S_{y x}, S_{D}$ and $R^{2}$. 
Information dimension (Evenness index)

The Shannon index is a general expression for statistical entropy, and is a measure of the complexity of a system. Seed-to-base pathways from the first order inflorescence branches of 0 ryzopsis hymenoides to the seed base were measured $(\mathrm{mm})$ :

$$
H=-\sum_{i=1}^{N} p_{i} \ln \left(p_{i}\right)
$$

where, $\mathrm{p}_{\mathrm{i}}=\mathrm{x}_{\mathrm{i}} / \Sigma_{\mathrm{i}} \mathrm{x}_{\mathrm{i}}, \mathrm{x}_{\mathrm{i}}$ is the seed-to-base pathway length for the ith seed, and $\mathrm{N}$ is the number of seeds. The maximum value of $\mathrm{H}$ is obtained when all seeds have equal seedto-base pathway lengths, $\mathrm{H}_{\max }=\ln (\mathrm{N})$. T he ratio $\mathrm{H} / \mathrm{H}_{\max }=\mathrm{J}$ is called the evenness (Erontier. 1987; Brooks \& Wiley, 1988). I thas the form of a fractal dimension, and has been called the information dimension (Schroeder, 1991, p. 221). This dimension measures the loss of information in the dynamic development of a chaotic system. Thus $J$ is an index of order, and is expected to decline under stress. Comparisons among treatments were accomplished as before by mixed model analysis of covariance.

\section{K orcak exponent}

The inflorescence of 0 . hymenoides trifurcates into three branches. Each branch point represents a new order or generation. Segment length and diameter decrease, on average, with respect to the preceding order (Durian theory). We calculated the hyperbolic distribution of the scalar relation between branch size, 1, and the number of branches $F_{1}$ of length at least 1 . By ordering the internode length of the inflorescence in order of magnitude and calculating the cumulative frequency $\left(F_{(1 \geq L)}\right)$ for categories of branches ranking $5 \mathrm{~mm}$ in decreasing order, $5,10,15$. . etc, we obtained a hyperbolic distribution for the scaling equation. The relation between number of occurrences ( $F$ ) and length (1) follows a power law:

$$
\mathrm{F}_{(1 \geq \mathrm{L})}=\mathrm{kl}^{-\beta}
$$

where $\beta$ is the $K$ orcak-M andelbrot exponent ( $H$ astings $\&$ Sugihara, 1993; Kaye 1993). The exponent $\beta$ represent the heterogeneity of inflorescence branch length. The larger the absolute value of $\beta$, the more heterogeneous is branch size. The standard error of the log-log regression $\left(S_{y x}\right)$, the standard error of the slope $\left(S_{\beta}\right)$, and one minus $\mathrm{R}^{2}$ were used in this study as indices of developmental instability.

\section{B ox counting fractal dimension}

We examined the fractal dimension of the branching system of $S$. novum. Photographs (slides) were taken of $\mathrm{S}$. novum branches during the spring, when the year's new biomass was fully grown. The branches were randomly chosen from among branches that had basal diameters of about $10 \mathrm{~mm}$, allowing us to standardize branch size. The fractal dimension of branch architecture was measured using a box counting method, i.e. by enclosing the projection of the plant in a grid of side $A$, divided into $(A / \lambda)^{2}$ squares of size $\lambda$. Square size ranged from 0.5 to $32 \mathrm{~mm}$, scaling in geometric progression with ratio equal 2 . Let $\mathrm{N}_{\lambda}$ be the number of squares of side $\lambda$ needed to cover the object. Then:

$$
\mathrm{N}_{\lambda}=\mathrm{b} \cdot \lambda^{-\mathrm{D}}
$$

where $\mathrm{D}$ is the fractal dimension of the projection of the plant onto a plane. By regressing $N_{\lambda}$ against the size $\lambda$, after logarithmic transformation, we obtain the slope of the regression (D) (Mandelbrot 1982). We used an analysis of covariance to determine the significance of grazing treatment on the fractal morphology of the plant, with the volume of the cylinder occupied by the aerial plant part as the covariate. 


\section{Results}

\section{Chrysothamnus greenii}

Internode length

The relation between internode length and node order fits $E$ qn (1). The significance value of the associated regression was $P<0.001$ for $93 \%$ of the cases ( 184 vS. 13 where the significance was lower). A veraged over all branches, $L=k \cdot N^{0.7} \cdot e^{-0.002 \mathrm{~N}}$. Eigure 1 present scatterplots of one representative case. In this figure we observe a good fit of the curve to the data point. T he standard error of the regression $\left(\mathrm{S}_{\mathrm{yx}}\right)$, and the standard error of the slope $a\left(S_{a}\right)$, are estimates of the curve's inaccuracy. Since $C$. greenii is not grazed by sheep, increased grazing should adversely affect competitors, alleviating stress on C. greenii. Therefore, the poorest curve fits should characterize low-grazing sites, the best fits the heavily grazed plants. As an inhabitant of disturbed areas, C. greenii should experience greatest stress at control sites where grazing is minimum.

O ur results show that grazing significantly influenced both the standard error of the regression and the standard error of the slope a $\left(F_{2,180}=6.24, p<0.002\right.$ and $F_{2,180}=7.47, p<0.001$ respectively; see [able 1). They indicate that as grazing increases the standard error of the regression and the standard error of the slope drops, as expected. Differences in $R^{2}$ were almost significant $\left(F_{2,180}=2 \cdot 31, p<0 \cdot 1\right)$.

In C. greenii the internode distance increases from the bottom to the top, except at the very top where this pattern is reversed. Thus (Eqn 1), the parameter a is positive and the parameter $b$ is negative, but small, because the effect is not highly apparent.

To determine if the grazing treatments affect internode length, we performed a mixed model analysis of variance on both parameter $a$ and parameter $b$, with grazing pressure as treatment, and stem nested in treatment. The results indicate that parameter a decreases significantly with increased grazing $\left(F_{2,180}=19 \cdot 26\right.$, $p<0.0001)$, making the internode length smaller ( $[$ able 1 ] $)$. The relationship between the parameter $b$ and grazing pressure is also significant $\left(F_{2,180}=23.95, p<0.0001\right)$.

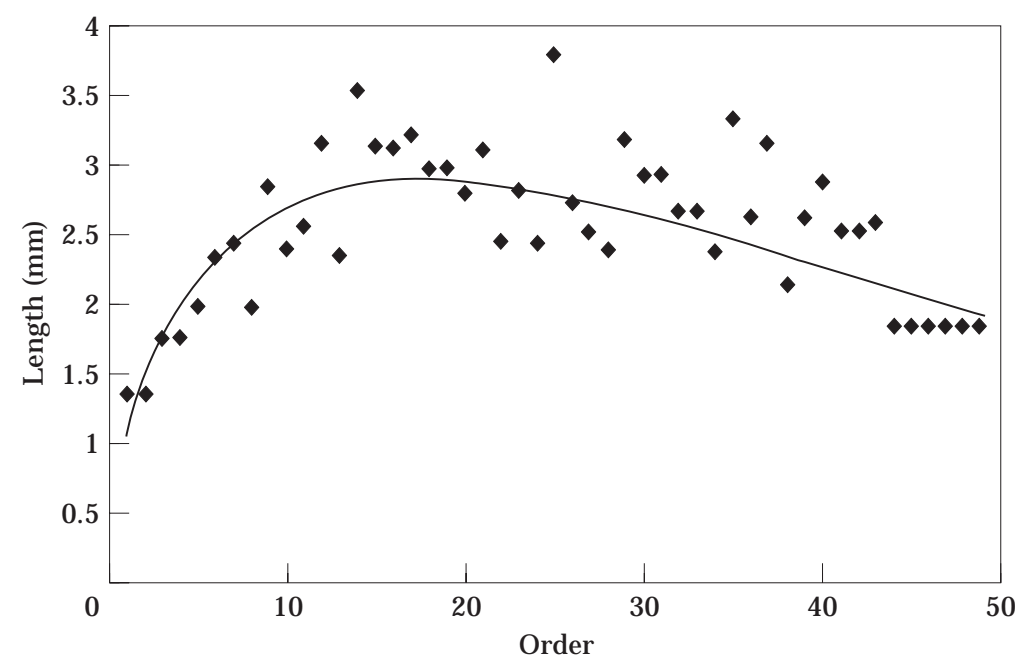

Figure 1 Scatterplots of the non-linear, best fit equation $L=1.10 \mathrm{~N}^{0.52} \mathrm{e}^{-0.03 \mathrm{~N}}$ for internode length (L) against order for one representative case in Chrysothamnus greenii. Equation parameters were obtained by least square regression analyses of the linearized equation (In $\mathrm{L}=\ln \mathrm{k}+\mathrm{a} \ln \mathrm{N}+\mathrm{bN})$. 
$\mathrm{H}$ igher grazing also leads to lower absolute values of the parameter $\mathrm{b}$ and thus slower decrease in internode length, particularly at the top of the stem ([able 1). In summary, grazing decreases the rate at which internode distance increase with node order, i.e. decreasing the distance between leaves.

\section{Cummulative frequency}

The cummulative frequency exponent represents the intensity of leaf formation; the larger the slope the larger is the increase in stem length with order and the fewer leaves are produced per stem length. In this case fractal dimension indicates the unfilled space between leaves. In consequence the scaling exponent should increase with stress, as observed (Table 2). T he error in the curve fitting also varied significantly among the grazing treatments. Plants in heavily-grazed areas had significantly lower standard error of the slope, standard error of the regression and higher regression coefficient than plants inhabiting medium-grazed and control treatments ([ able 2).

\section{O ryzopsis hymenoides}

Information dimension

0 ryzopsis hymenoides is not eaten by sheep during the winter because the above-ground part of the plant is dead. Therefore, 0 . hymenoides should behave like $C$. greenii; heavy grazing alleviates stress from competitors. On the other hand, 0 . hymenoides is adapted to undisturbed conditions, suggesting low stress also in the control area. Light and

Table 1. $M$ ean $\pm S E(N)$ and $F$ values of the mixed model analysis of variance, comparing scale asymmetry parameters $\left(S_{y x}, S_{a}\right.$, and $\left.R^{2}\right)$, equation parameters a and $b$ from the leaf arrangement equation $\ln L=\ln k+a$. $\ln N-b . N$, under three different grazing pressures

\begin{tabular}{ccccc}
\hline & Control & \multicolumn{1}{c}{ M edium } & High & $\mathrm{F}_{(2,180)}$ \\
\hline $\mathrm{S}_{\mathrm{yx}}$ & $0.34 \pm 0.02(78)^{\mathrm{a}}$ & $0.29 \pm 0.03(29)^{\mathrm{ab}}$ & $0.25 \pm 0.01(90)^{\mathrm{b}}$ & $6.24^{* *}$ \\
$\mathrm{~S}_{\mathrm{a}}$ & $0.20 \pm 0.01(78)^{\mathrm{a}}$ & $0.18 \pm 0.02(29)^{\mathrm{ab}}$ & $0.14 \pm 0.01(90)^{\mathrm{b}}$ & $7.47^{*} * *$ \\
$\mathrm{R}^{2}$ & $0.69 \pm 0.02(78)^{\mathrm{a}}$ & $0.62 \pm 0.03(29)^{\mathrm{a}}$ & $0.68 \pm 0.02(90)^{\mathrm{a}}$ & 2.31 \\
$\mathrm{a}$ & $0.98 \pm 0.06(78)^{\mathrm{a}}$ & $0.65 \pm 0.09(29)^{\mathrm{b}}$ & $0.47 \pm 0.05(90)^{\mathrm{b}}$ & $19.26 * * *$ \\
$\mathrm{~b}$ & $0.05 \pm 0.005(78)^{\mathrm{a}}$ & $0.03 \pm 0.008(29)^{\mathrm{b}}$ & $0.0008 \pm 0.004(90)^{\mathrm{c}}$ & $23.95^{* * *}$ \\
\hline
\end{tabular}

$* * * p<0.0001 ; * * p<0.001 ; * p<0.05 ;$ no asterisks indicates $p>0.05$.

a-cM eans with the same letters show no significant differences at the 0.05 level, Tukey test.

Table 2. M ean $\pm S E(N)$ and $F$ values of the mixed model analysis of variance, comparing scale asymmetry parameters $\left(S_{y x}, S_{D}\right.$, and $\left.R^{2}\right)$, and slope $(D)$ in the cummulative frequency equation $\left(\Delta \mathrm{L}_{(\mathrm{N})}=\mathrm{kN} \mathrm{D}\right)$ of $\mathrm{C}$ hrsothamnus greenii

\begin{tabular}{ccccr}
\hline & Control & M edium & High & $F_{(2,172)}$ \\
\hline $\mathrm{D}$ & $1.51 \pm 0.02(70)^{\mathrm{a}}$ & $1.36 \pm 0.04(28)^{\mathrm{b}}$ & $1.37 \pm 0.02(80)^{\mathrm{b}}$ & $10.05 * * *$ \\
$\mathrm{~S}_{\mathrm{yx}}$ & $0.16 \pm 0.01(70)^{\mathrm{a}}$ & $0.12 \pm 0.02(28)^{\mathrm{a}}$ & $0.09 \pm 0.01(80)^{\mathrm{b}}$ & $12 \cdot 39 * * *$ \\
$\mathrm{~S}_{\mathrm{D}}$ & $0.036 \pm 0.003(70)^{\mathrm{a}}$ & $0.036 \pm 0.005(28)^{\mathrm{a}}$ & $0.02 \pm 0.003(80)^{\mathrm{b}}$ & $8.89 * * *$ \\
$\mathrm{R}^{2}$ & $0.982 \pm 0.002(70)^{\mathrm{a}}$ & $0.988 \pm 0.003(28)^{\mathrm{ab}}$ & $0.993 \pm 0.002(80)^{\mathrm{b}}$ & $9.84 * * *$ \\
\hline
\end{tabular}

$* * * p<0.0001 ; * * p<0.001 ; * p<0.05 ;$ no asterisks indicates $p>0.05$.

a-cM eans with the same letters show no significant differences at the 0.05 level, Tukey test. 
intermediate grazing might stimulate growth of foraging species which compete with 0 . hymenoides causing stress.

Information dimension is a measure of complexity. U sing a mixed model analysis of covariance, we compared the relationship between the J index and grazing intensity. Plant crown diameter was a covariant. The results indicate that grazing significantly impacts $\left(F_{3,154}=3 \cdot 11, p<0.05\right)$. Significant differences also occured between the replicates, but since the interaction between grazing and replicate is not significant $\left(F_{3,151}=0.556, N S\right)$, we conclude that grazing treatment significantly influences the information dimension. As expected, J increases under high $(0.988 \pm 0.001, N=40)$ and natural (control) $(0.987 \pm 0.001, N=39)$ grazing, and declines under light $(0.985 \pm 0.001, N=40)$ and medium $(0.985 \pm 0.001, N=41)$ grazing.

\section{K orcak exponent}

T he K orcak exponent is related to the number of ramifications of the inflorescence. A linear regression between the seed number and the $\beta$ exponent is significant $\left(R^{2}=0.09, \mathrm{df} .=155\right.$, slope $\left.=0.007, t=4.01, p=0.0001\right)$. The larger the number of ramifications, the higher is the $\beta$ exponent. The $\beta$ exponent is not significantly related to grazing intensity $\left(F_{3,149}=0 \cdot 273, N S\right)$. B ecause developmental instability is the degree to which disturbances lead to exaggerated intra-individual variance, the accuracy in fits of the scalar equation may be a measure of developmental stability; under stress conditions $S_{y x}$ and standard error of the slope, $S_{\beta}$, should increase. Results of the two way analysis of variance ( $($ Iable 3 ) indicate that grazing significantly affects the standard error of the regression in 0 . hymenoides when size is controlled $\left(F_{3,149}=2.584, p=0.05\right)$. The standard error of the slope $\left(S_{\beta}\right)$ also differs significantly among the grazing treatments $\left(F_{3,149}=4.433, p=0.005\right)$, i.e. $S_{\beta}$ is lowest in the control and heavy grazing treatments. D ifferences in $R^{2}$ are not significant.

\section{Seriphidium novum}

Internode length

The multiple regression of log internode length on node number and log node number (Eqn 2) was performed, and for $78 \%$ of the cases the significance value of the associated analysis of variance was $p<0.05$ (in 13 out of 59 cases the significance was lower). The equation obtained with the mean values over all treatments is $\mathrm{L}=\mathrm{k} \cdot \mathrm{N}^{0.93} \cdot \mathrm{e}^{-0 \cdot 12 \mathrm{~N}}$. A scatterplot of one representative case is presented in Eig.2. In this figure we also observe a good fit of the curve to the data point.

To determine if grazed and ungrazed plants exhibit different levels of developmental instability, we compared $\mathrm{S}_{\mathrm{yx}}, \mathrm{S}_{\mathrm{a}}$ and $\mathrm{R}^{2}$ for grazed and ungrazed treatments using a nested analysis of covariance with two stems measured per plant, and mean crown diameter as covariant. The results do not indicate any significant difference for $\mathrm{S}_{\mathrm{a}}$

Table 3. $M$ ean $\pm S E(N)$ and $F$ values of the mixed model analysis of variance, comparing scale asymmetry parameters $\left(S_{y x}, S_{p}\right.$, and $\left.R^{2}\right)$, and slope $(\beta)$ in the cummulative frequency equation $\left(\mathrm{F}_{(\mathrm{I} \geq \mathrm{L})}=\mathrm{kl}-\beta\right)$ of Oryzopsis hymenoides

\begin{tabular}{cccccc}
\hline & Control & Low & M edium & High & $F_{(3,149)}$ \\
\hline$\beta$ & $1.34 \pm 0.07(40)^{a}$ & $1.42 \pm 0.07(39)^{a}$ & $1.42 \pm 0.07(40)^{a}$ & $1.38 \pm 0.07(38)^{a}$ & 0.27 \\
$S_{y x}$ & $0.66 \pm 0.03(40)^{a}$ & $0.72 \pm 0.03(39)^{a b}$ & $0.79 \pm 0.03(40)^{b}$ & $0.73 \pm 0.03(38)^{a b}$ & $2.58^{*}$ \\
$S_{\beta}$ & $0.035 \pm 0.03(40)^{a}$ & $0.037 \pm 0.02(39)^{a}$ & $0.44 \pm 0.02(40)^{b}$ & $0.36 \pm 0.02(38)^{a}$ & $4.43^{* *}$ \\
\hline
\end{tabular}

$* * * p<0.0001 ; * * p<0.001 ; * p<0.05 ;$ no asterisks indicates $p>0.05$.

a-cM eans with the same letters show no significant differences at the 0.05 level, Tukey test. 
$\left(F_{1,54}=0.25, N S\right)$, nor for $R^{2}\left(F_{1,54}=0.08, N S\right)$, although a tendency towards larger standard error of the regression $\left(S_{y x}\right)$ is observed for ungrazed plants $\left(F_{1,54}=2 \cdot 21\right.$, $\mathrm{p}<0.1, \quad$ Syx $_{\text {ungrazed }}=0.35, \quad \mathrm{~N}=30, \quad \mathrm{SE}=0.02, \quad \operatorname{Syx}_{\text {grazed }}=0.31, \quad \mathrm{~N}=29$, $\mathrm{SE}=0.02$ ).

To determine if grazing affects the parameter values in the equation, we performed a nested analysis of covariance with mean crown diameter as covariant. The parameter a declines under heavy grazing from $1(\mathrm{~N}=30, \mathrm{SE}=0.08)$ in the non-grazed exclosure, to $0.85(N=29, S E=0.08)$ with grazing $\left(F_{1,54}=3.75, p<0.06\right)$. As in $C$. greenii, the parameter a increases under higher stress conditions, increasing the distance between leaves. $\mathrm{N} o$ trend is observed for the parameter $b\left(F_{1,54}=0 \cdot 10\right.$, NS).

\section{F ractal dimension}

F ractal dimension is a measure of the efficiency with which plants fill space. Plants with many terminal branches should have higher fractal dimension than plants with poorly developed branching. Prior analyses demonstrated that internode length increases with stress. That is, stress produces plants with fewer leaves. Therefore, fractal dimension should decline under stress conditions.

Although the measures of developmental instability reported above did not differ significantly between the grazed and ungrazed treatments, there was a tendency toward higher instability under the ungrazed treatment. Consequently, we do not necessarily expect significant differences in fractal dimension, but if a tendency is observed it must be towards a reduction in dimension under ungrazed treatment. A one-way analysis of covariance produced a $p<0.1$ level of significance $\left(F_{1,34}=2.56\right)$, with mean dimension $=1.54(\mathrm{~N}=17, \mathrm{SE}=0.02)$ for ungrazed plants, mean dimension $=1.58(\mathrm{~N}=20, \mathrm{SE}=0.01)$ for grazed plants, in keeping with our expectations.

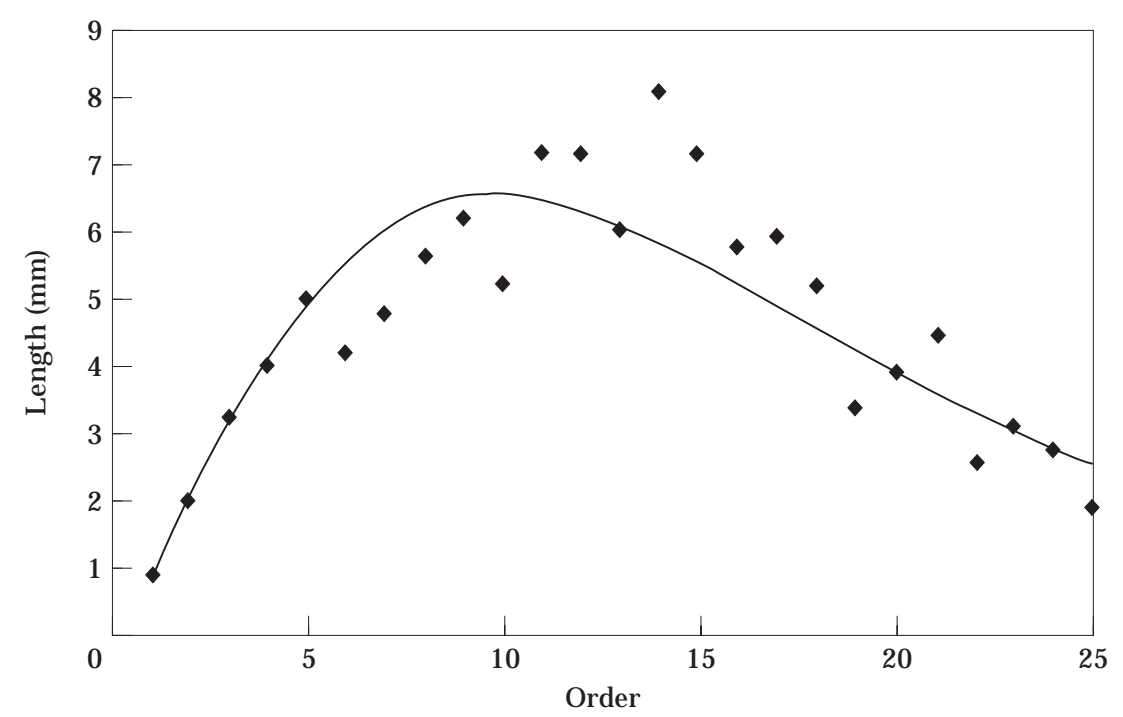

Figure 2 Scatterplots of the non-linear, best fit equation $L=0.91 \mathrm{~N}^{1.55} \mathrm{e}^{-0.16 \mathrm{~N}}$ for internode length $(L)$ against order for one representative case in Seriphidium novum. Equation parameters were obtained by least square regression analyses of the linearized equation ( $\ln L=\ln k+a \ln$ $\mathrm{N}+\mathrm{bN}$ ). 


\section{Discussion}

$\mathrm{N}$ ot all developmental instability measurements are equally sensitive to stress (Soulé\& Cuzin-Roudy. 1982: Ereeman et al. 1993; Graham et al. 1993a). Sensitivity depends on the degree of canalization (Waddinaton. 1942), on the non-linear dynamics of development at the molecular level (Emlen et al. 1993), and on non-linear feedback processes regulating allometric growth (Graham et al., 1993b). It would be useful to define the more sensitive indices of stress for use as stress detection tools. Here, we examine the usefulness of several such indices vis-á-vis stress from plant competition under grazing pressure.

When studying developmental instability in plants, we should take into account that plants, in contrast to animals, are very plastic organisms. Plasticity, accordingly to B radshaw (1965), is the ability of an organism to alter its physiology or morphology in response to environmental changes. Its phenotypic differences are consistent in sign among generations and have a genetic origin. In contrast, developmental instability is the random intra-individual variation of a character which is not genetic in origin. It is the result of error during development (Mather, 1953). D evelopmental stability, on the other hand, is the ability of an organism to buffer environmental and genetic disturbances during development, it has a genetic component but is controlled by a different genetic system, as has been demonstrated in A rabidopis thaliana ( $L$.) H eynh. by Bagchi \& _yama (1983). It is based on the assumption that stabilizing selection maintains a well integrated combination of genes acting to reduce intra-individual variation in repeated structures with identical genetic and environmental influences. In consequence, one can use any phenotypic trait to measure developmental instability provided that one a priori knows what phenotype should be produced in the absence of stress. This seemingly impossible task is actually rather simply achieved by examining traits that do not normally vary during development, i.e. developmental invariants (Graham et al. 1993a).

Studies in animals have demonstrated that it is preferable to avoid traits with strong stabilizing selection, for example traits that directly and strongly affect fitness (5oulé \& Cuzin-Roudy 1982, Parsons, 1990). On the contrary, in choosing measures of developmental instability in plants, it is more useful to consider structural details and to select highly canalized characters in order to avoid masking developmental error by high variability.

In this study we observe that grazing clearly affected the intra-individual variability of $\mathrm{C}$. greenii and $\mathrm{O}$. hymenoides. H owever, for $\mathrm{S}$. novum, there was no difference in the levels of instability between the control and heavily grazed treatments. Species that are either dormant at the time of grazing ( 0 . hymenoides) or are not grazed (C. greenii) show the lowest level of developmental instability in the most heavily grazed treatments. These results are consistent with most studies of grazing (see Belsky (1986. 1987) for reviews), which show that grazing reduces the abundance of competitors. Thus, unpalatable species are expected to have the highest level of developmental instability in the highly competitive (i.e. ungrazed) treatments and the lowest level of developmental instability in the least competitive (most heavily grazed) environments, as observed. Conversely, palatable species that are dormant during the winter-spring grazing period are expected to, and do exhibit elevated levels of developmental instability under moderate grazing. $\mathrm{N}$ atural grazing pressure enhances developmental stability in species habituated to moderate grazing, such as 0 . hymenoides. Seen in this light, the response of $S$. novum is not surprising. We examined this species in only two treatments, an ungrazed control (highly competitive) and a heavily grazed treatment. The failure to find elevated levels of developmental instability in the control vs. the heavily grazed treatment does not invalidate the technique, because in fact both habitats are stressful. What differs is the nature of the stress. This points out one of the unique advantages of developmental instability as a measure of stress; it can be used 
to resolve the controversy over whether light to moderate grazing enhances the fitness of grazed plants directly (see M cN aughton, 1977, 1979|, 1983; Collins, 1987; Escós et 1.. 1997) or, alternately, arises indirectly from a release from competition (see Belsky. $1986[1987)$. O ur results support the contention that grazing reduces competition.

Efficiency of transport systems in animals can be enhanced by increasing the surface area available for absorption through the intestine, or by proliferation in the branching of blood vessels, bile ducts and bronchial trees (Erontier, 1987; West $\varepsilon$ Goddherger 1987, Goldberger et al, 1990). In similar vein, it is expected that increased complexity of branch structure, which can be measured by fractal geometry, enhances energy flow and nutrient cycling in plants. For example, the branching structure of trees may allow sufficient contact between plant and atmosphere for efficient photosynthetic and metabolic gas exchange (Erontier, 1987; Zeide \& P feifer, 1997). F ractal structure al so is a form of symmetry, in this case invariance with scale. The ultimate importance of fractal analysis for developmental instability analysis is not well known (Glenny et al. 1991) Emlen et al., 1993). In this study we observe that the fractal dimension of branch architecture declines as stress increases. In the same way, fractal dimension of the root system in Zea mays L. declines under nitrogen stress (Eghball et al. 1993). This result is consistent with changes in the parameter values of the leaf and branch arrangement equations, which lead to increased foliage (shorter internode length) and larger branches under unstressed situations. Similar results are observed in another grazed shrub, A nthyllis cytisoides L. (Alados et al. 1994; Escós et al. 1997). The cumulative frequency exponent represents the intensity of leaf formation; the larger the exponent, the longer the internode enhancement and the lower the density of the leaves. In consequence, the cumulative frequency scaling exponent declines with increased disturbance.

The results shown here are important in other ways. D evelopmental instability is usually assessed as a departure from symmetry. F luctuating asymmetry, for example, measures departures from bilateral symmetry. There are other forms of symmetry. F or example, where internode length or diameter scales with node number, one can translate any point on the regression line to any other simply by using the scaling relationship. Therefore, dispersion about the regression line becomes a measure of the departure from perfect translational symmetry. As noted above, grazing does indeed increase the dispersion about the regression line as predicted. G razing also changes the allometric relationship between node number and internode length, i.e. the parameters of the regression lines. These changes may occur in conjunction with changes in the dispersion about the line (C. greenii), and therefore may be attributed to poor curve fitting. O ur results suggest that the allometric relationships themselves also contain information about stress. Thus, it would appear that a combination of both allometric measures and symmetry measures can be used to assess the impact of grazing on the architecture of plants.

We thank the Desert Experimental Range Station from the U.S. Forest Service, Dept. of A griculture at $U$ tah for granting us free access to its facilities. The work was supported by the Comisión Interministerial de Ciencia y T ecnologia, project number AM B 93-0777-C 02-01.

\section{References}

Alados, C.L., Escós, J. \& Emlen, J.M . (1994). Scale asymmetry: a tool to detect developmental instability under the fractal geometry scope. In: N ovak, M.M. (Ed.), F ractals in the $\mathrm{N}$ atural and A pplied Sciences, pp. 25-36. N orth-H olland: Elsevier Science B. V. 451 pp.

Alados, C.L., Escós, J. \& Emlen, J.M . (1996). Fractal structure of sequential behavior patterns: an indicator of stress. A nimal B ehaviour, 51 437-443.

Alados, C.L., Navarro, T., Cabezudo, B., Emlen, J.M. \& Freeman, C.D. (in press). D evelopmental instability in gynodioecicus T eucrium lusitanicum. E volutionary E cology.

Avnir, D. (1990). The Fractal A pproach to $H$ eterogeneous Chemistry. Chichester: John Wiley \& Sons. $441 \mathrm{pp}$. 
Bagchi, S. \& Iyama, S. (1983). Radiation induced developmental instability in Arabidopsis thaliana. Theoretical A pplied G enetics, 65: 85-92.

Bassingthwaighte, J.B., L iebovitch, L.S. \& W est, B.J. (1994). F ractal Physiology. Oxford: Oxford U niversity Press. $354 \mathrm{pp}$.

Beacham, T.D. (1990). A genetic analysis of meristic and morphometric variation in chum salmon (O ncorhynchus keta) at three different temperatures. Canadian J ournal of Fisheries and A quacultural Science, 68: 225-229.

Beardmore, J.A. (1969). D evelopmental stability in constant and fluctuating temperatures. H eredity, 14: 411-422.

Belsky, A.J. (1986). Does herbivory benefit plants? A review of the evidence. American N aturalist, 127: 870-892.

B elsky, A.J. (1987). The effects of grazing: confounding of ecosystem, community and organism scales. A merican N aturalist, 129. 777-783.

B radshaw, A.D . (1965). Evolutionary significance of phenotypic plasticity in plants. A dvances in Genetica, 31: 115-155.

Brooks, D.R. \& Wiley, E.O. (1988). Evolution as Entropy. T oward a unified theory of biology (2nd Edn). Chicago: The U niversity of Chicago Press. 415 pp.

Brown, V.K. \& Gange, A.C. (1989). D ifferential effects of above- and below-ground insect herbivory during early plant succession. O ikos, 54: 67-76.

Bunde, A. \& H avlin, S. (1995). Fractals in Science. Berlin: Springer-Verlag. 298 pp.

Cargill, S.M . \& Jefferies, R.L. (1984). The effects of grazing by lesser snow geese on the vegetation of a sub-arctic salt marsh. J ournal of A pplied E cology, 21: 669-686.

Clary, W.P. \& H olmgren, R.C. (1982). D esert Experimental Range: establishment and research contribution. Rangelands, 4: 261-264.

Collins, S.L. (1987). Interaction of disturbances in tall grass prairie: a field experiment. E cology, 68: $1243-1250$.

Crawley, M .J. (1983). H erbivory, the dynamics of animal-plant interactions. Berkeley: U niversity of California Press. 437 pp.

Crawley, M .J. (1987). Benevolent herbivores? Trends in Ecology and Evolution, 2 167-168.

Crawley, M.J. (1992). Herbivory and I pomopsis aggregata: the disadvantages of being eaten. A merican N aturalist, 139: 870-882.

D oak, D.F. (1991). The consequences of herbivory for dwarf fireweed: different time scales, different morphological scales. Ecology, 72: 1397-1407.

Edenius, L., D anell, K.\& Bergström, R. (1993). Impact of herbivory and competition on compensatory growth in woody plants: winter browsing by moose in Scots pine. Oikos, 66: 286-292.

Eghball, B., Settimi, J.R., M aranville, J.W. \& Parkhurst, A.M . (1993). Fractal analysis for morphological description of corn roots under nitrogen stress. A gronomy J ournal, 85: 287-289.

Emlen, J.M., Freeman, D.C. \& Graham, J.H. (1993). N onlinear growth dynamics and the origin of fluctuating asymmetry. G enetica, 89: 77-96.

Escós, J., Alados, C.L.\& Emlen, J.M. (1995a). D evelopmental instability in the Pacific hake parasitized by Myxosporeans Kudoa spp. Transaction of American Fisheries Society, 124: 943-945.

Escós, J., Alados, C.L. \& Emlen, J.M. (1995b). Fractal structures and fractal functions as disease indicators. 0 ikos, 74: 310-314.

Escós, J., Alados, C.L. \& Emlen, J.M . (1997). G razing impact on plant fractal architecture and fitness of a M editerranean shrub (A nthyllis cytisoides L.). F unctional E cology, 11. 66-78.

Fowler, N.L. \& Rausher, M .D. (1985). Joint effects of competitors and herbivores on growth and reproduction in A ristolochia reticulata. Ecology, 66: 1580-1587.

Freeman, D.C., Graham, J.H.\& Emlen, J.M. (1993). Developmental stability in plants: symmetries, stress and epigenesis. G enetica, 89. 97-119.

Freeman, D.C., Graham, J.H., Byrd, D.W., M cArthur, E.D. \& T urner, W .A. (1995). N arrow hybrid zone between two subspecies of big sagebrush, A rtemisia tridentata (Asteraceae). III. D evelopmental instability. A merican J ournal of B otany, 82 144-152.

Frontier, S. (1987). Applications of fractal theory to ecology. In: Legendre, P. (Ed.), Developments in Numerical Ecology. NATO ASI Series-Vol. G14, pp. 335-378. Berlin, $\mathrm{H}$ eidelberg: Springer-Verlag.

Glenny, R.W., Robertson, H.T., Y amashiro, S. \& Bassingthwaighte, J.B. (1991). A pplications of fractal analysis to physiology. J ournal of A pplied Physiology, 70. 2351-2367. 
Goldberger, A.L., Rigney, D.R. \& West, B.J. (1990). Chaos and fractals in human physiology. Scientific A merican, Feb: 35-41.

Graham, J.H ., Freeman, D.C. \& Emlen, J.M . (1993a). D evelopmental stability: A sensitive indicator of population under stress. In: Landis, W.G., Hughes, J.S. \& L ewis, M.A. (Eds), Environmental T oxicology and R isk A ssessment, pp. 136-158. ASTM ST P 1179. Philadel phia, PA: A merican Society for T esting and $M$ aterials.

Graham, J.H., Freeman, D.C. \& Emlen, J.M . (1993b). Antisymmetry, directional asymmetry, and dynamic morphogenesis. G enetica, 89. 121-137.

H arper, J.L. (1977). Population Biology of Plants. N ew York: Academic Press. 892 pp.

H asting, H.M . \& Sugihara, G . (1993). Fractals: a user's guide for the natural sciences. Oxford: Oxford U niversity Press. $235 \mathrm{pp}$.

$\mathrm{H}$ utchings, S.S. (1966). G razing management of salt-desert shrub ranges in the western U nited States. IX. International G rassland Congress Proceedings, Vol. 2, pp. 1619-1625. Sao Paulo, Brazil.

Jefferies, R.L. (1988). Vegetation mosaics, plant-animal interactions and resources for plant growth. In: Gottlieb, L.D. \& Jain, S.K. (Eds), Plant Evolutionary Biology, pp. 340-361. L ondon: Chapman \& Hall.

K aye, B. (1993). Chaos and Complexity. Weinheim: VCH. 593 pp.

K imura, M . (1960). Primary production of the warm-temperate laurel forest in the southern part of Osumi Peninsula. M iscellaneous Reports of Research Institute for $\mathrm{N}$ atural Resources ( Tokyo), 52/53: 36-47.

K ohyama, T . (1987). Significance of architecture and allometry in saplings. F unctional E cology, 1. $399-404$

Ludwig, W. (1932). Das R echts-Links Problem in Tierreich und beim M enschen. Berlin: SpringerVerlag.

M andelbrot, B.B. (1982). The F ractal G eometry of N ature. San Francisco: F reeman. 460 pp.

M arkow, T .A. (1994). Contemporary I ssues in G enetics and E volution. D evelopmental instability: I ts origins and evolutionary implications. D odrecht: K luwer A cademic Publishers. 335 pp.

$M$ arquis, R.J. (1984). Leaf herbivores decrease fitness of a tropical plant. Science, 226: 537-539.

M arquis, R.J. (1992). A bite is a bite? Constraints on response to folivory in Piper arieianum (Piperaceae). E cology, 73: 143-152.

M aschinski, J. \& Whitham, T.G . (1989). The continuum of plant responses to herbivory: the influence of plant association, nutrient availability, and timing. A merican $\mathrm{N}$ aturalist, $\mathbf{1 3 4}$ 1-19.

M ather, K. (1953). G enetic control of stability in development. H erdity, 7: 297-336.

M clnnes, P.F., N aiman, R.J., Pastor, J. \& C ohen, Y. (1992). Effects of moose browsing on vegetation and litter of the boreal forest, Isle Royale, M ichigan, USA. Ecology, $\mathbf{7 3}$ : 2059-2075.

M cK enzie, J.A. \& Clarke, G.M . (1988). Diazinon resistance, fluctuating asymmetry and fitness in the Australian sheep blowfly L ucilia cuprina. G enetics, 120. 213-220.

M cN aughton, S.J. (1977). Diversity and stability of ecological communities: a comment on the role of empiricism in ecology. A merican N aturalist, 111 515-525.

M cN aughton, S.J. (1979). G razing as an optimization process: grass-ungulate relationships in the Serengeti. A merican N aturalist, 113: 691-703.

M cN aughton, S.J. (1983). Compensatory plant growth as a response to herbivory. Oikos, 40. 329-336.

M cN aughton, S.J. (1986). On plants and herbivores. A merican $N$ aturalist, 128: 765-770.

Møller, A.P. (1995a). L eaf-mining insects and fluctuating asymmetry in elm U Imus glabra leaves. J ournal of A nimal Ecology, 64: 697-707.

M øller, A.P. (1995b). Parasitism and developmental instability of hots- a review. 0 ikos, 77: 189-196.

M øller, A.P. \& E riksson, M . (1994). Patterns of fluctuating asymmetry in flowers: Implications for sexual selection in plants. J ournal of Evolutionary Biology, 7: 97-113.

M øller, A.P. \& Eriksson, M . (1995). Pollinator preference for symmetrical flowers and sexual selection in plants. Oikos, 73: 15-22.

M ontalvo, J., C asado, M .A., L evassor, C . \& Pineda, F.D. (1993). Species diversity patterns in M editerranean grasslands. J ournal of $V$ egetation Science, 4: 213-222.

Niklas, K.J. (1992). Plant Biomechanics. An engineering approach to plant form and function. Chicago \& L ondon: The U niversity of Chicago Press. 607 pp. 
Oesterheld, M. (1992). Effect of defoliation intensity on aboveground and belowground relative growth rates. 0 ecologia, 92 313-316.

O gawa, H.\& Kira, T. (1977). M ethods of stimating forest biomass. In: Shidei, T . \& K ira, T . (Eds), Primary Productivity of Japanese Forests, pp. 15-25. JIBP Synthesis 16. Tokyo: U niversity of T okyo Press.

Palmer, A.R. \& Stobeck, C. (1986). Fluctuating asymmetry: measurement, analysis, patterns. Annual Review of Systematic, 17: 391-421.

Parsons, P.A. (1990). Fluctuating asymmetry: an epigenetic measure of stress. B iological R eview, 65: $131-145$

Polak, M. (1994). Parasites increase fluctuating asymmetry of male D rosophila nigrospiracula: implications for sexual selection. In: M arkow, A. (Ed.), D evelopmental Instability: its origins and evolutionary implications, pp. 257-267. Dordrecht: Kluwer Academic Publishers. $335 \mathrm{pp}$.

Ruess, R.W. \& M cN aughton, S.J. (1987). Grazing and the dynamics of nutrient and energy related microbial processes in the Serengeti grasslands. 0 ikos, 49. 101-110.

Ruess, R.W., H ik, D.S. \& Jefferies, R.L. (1989). The role of lesser snow geese as nitrogen processors in a sub-arctic salt marsh. 0 ecologia, 79. 23-29.

Schroeder, M . (1991). F ractals, Chaos, Power L aws. N ew Y ork: W.H . F reeman and Company. $429 \mathrm{pp}$.

Sherry, R. \& Lord, E.M. (1996). Developmental stability in leaves of Clarkia tembloriensis (Onagraceae) as related to population outcrossing rates and heterozygosity. Evolution, 50: 80-91.

Siegel, M .I. \& D oyle, M .J. (1975a). T he differential effects of prenatal and postnatal audigenic stress on fluctuating asymmetry. J ournal of Experimental Zoology, 191: 211-214.

Siegel, M.I. \& Doyle, M.J. (1975b). The effect of cold stress on fluctuating asymmetry in the dentition of the mouse. J ournal of Experimental Zoology, 193: 385-389.

Siegel, M .I \& D oyle, M .J. (1975c). Stress and fluctuating limb asymmetry in various species of rodents. G rowth, 39. 363-369.

Siegel, M.I. \& Smookler, H.H. (1973). Fluctuating dental asymmetry and audigenic stress. Growth, 37: 35-39.

Siegel, M .I., D oyle, M .J. \& K elley, C . (1977). H eat stress, fluctuating asymmetry, and prenatal selection in the laboratory rat. A merican J ournal of Physiology and Anthropology, 46: 121-126.

Soulé, M.E. \& C uzin-Roudy, J. (1982). Allomeric variation. 2. Developmental instability of extreme phenotypes. A merican N aturalist, 120. 765-786.

Sumner, F.B. \& H uestis, R.R. (1921). Bilateral asymmetry and its relation to certain problems of genetics. $G$ enetics, $6: 445-485$.

T racy, M ., Freeman, D.C., Emlen, J.M ., G raham, R.A. \& H ough, R.A. (1995). D evelopmental instability as a biomonitor of environmental stress: an illustration using aquatic plants and macroalgae. In: Butterworth, F.M ., C orkum, L.D.\& Guzmán-Rincón, J. (Eds), Biomonitors and B iomarkers as Indicators of Environmental Change, pp. 313-338. Environmental Science Research 50. N ew Y ork: Plenum Press. $348 \mathrm{pp}$.

T rlica, M .J. \& Rittenhouse, L.R. (1993). G razing and plant performance. E cological A pplications, 3: $21-23$.

Valentine, D.W. \& Soulé, M.E. (1973). Effect of p,p'-DDT on developmental stability of pectoral fin rays in the grunion, L euresthes tenius. Fisheries B ulletin, 71: 920-921.

Van Valen, L. (1962). A study of fluctuating asymmetry. E volution, 16: 125-142.

Waddington, C.H. (1942). Canalization of development and the inheritance of acquired characters. N ature, 150: 563-565.

West, B.J. \& G oldberger, A.L. (1987). Physiology in fractal dimensions. A merican Scientistic, 75: 354-365.

Zakharov, V.M ., Pankakoski, E., Sheftel, B.I ., Peltonen, A . \& H anski, I. (1991). D evelopmental stability in the common shrew Sorex araneus. A merican $N$ aturalist, 138: 797-810.

Zeide, B. \& Pfeifer, P. (1991). A method for estimation of fractal dimension of tree crowns. Forest Science, 37: 1253-1265. 